\title{
MODULAR INEQUALITIES FOR THE HARDY-LITTLEWOOD AVERAGES
}

\author{
DAH-CHIN LUOR
}

Abstract. In this paper we establish general inequalities of the Hardy-Littlewood averages. We apply our results to obtained the higher-dimensional form of a strengthened Hardy-Knopp-type inequality. Furthermore, we discuss the inequalities given by Čižmešija et. al. [1], Cochran and Lee [2], Heinig [5], S. Kaijser et. al. [6], Levinson [8], Love [9 10], and Xiao [12], and show that these results are special cases of our results in this paper.

Mathematics subject classification (2010): Primary 26D10; Secondary 26D15. inequality.

Keywords and phrases: Hardy-Littlewood averages, modular inequality, Hardy's inequality, Knopp's

\section{REFERENCES}

[1] A. ČIŽMeŠIJA, J. PeČARIĆ, AND L.-E. Persson, On strengthened Hardy and Pólya-Knopp's inequalities, J. Approx. Theory, 125 (2003), 74-84.

[2] J. A. Cochran AND C.-S. LeE, Inequalities related to Hardy's and Heinig's, Math. Proc. Cambridge Philos. Soc., 96 (1984), 1-7.

[3] G. H. Hardy, Divergent Series, Oxford University Press, Oxford, 1949.

[4] G. H. Hardy, J. E. LitTlewood, AND G. Pólya, Inequalities, 2nd edition, Cambridge University Press, Cambridge, 1952.

[5] H. P. HeINIG, Modular inequalities for the Hardy averaging operator, Mathematica Bohemica, 124 (1999), 231-244.

[6] S. Kaijser, L.-E. Persson, And A. ÖBerg, On Carleman and Knopp's inequalities, J. Approx. Theory, 117 (2002), 140-151.

[7] A. KUfner AND L.-E. Persson, Weighted inequalities of Hardy type, World Scientific Publishing Co., New Jersey, London, Singapore, Hong Kong, 2003.

[8] N. LeVInson, Generalizations of an inequality of Hardy, Duke Math. J., 31 (1964), 389-394.

[9] E. R. Love, Inequalities related to those of Hardy and of Cochran and Lee, Math. Proc. Cambridge Philos. Soc., 99 (1986), 395-408.

[10] E. R. Love, Inequalities related to Knopp's inequality, J. Math. Anal. Appl., 137 (1989), 173-180.

[11] B. Opic And A. Kufner, Hardy-type inequalities, Pitman Research Notes in Mathematics Series 219, Longman Scientific \& Technical Harlow, 1990.

[12] J. XIAO, $L^{p}$ and BMO bounds of weighted Hardy-Littlewood averages, J. Math. Anal. Appl., 262 (2001), 660-666. 